\title{
EL CONTROL DE LEGALIDAD Y LA SUSPENSION DE ACUERDOS DE LOS ENTES TERRITORIALES POR EL ESTADO
}

340.131 .5

por

Andrés Morey

SUMARIO: I. INTRODUCCION.-II. LA REGULACION ANTERIOR A LA CONSTITUCION DE 1978.-III. LA REGULACION A PARTIR DE LA CONSTITUCION DE 1978: 1. LA CUESTIÓN EN LA CONSTITUCIÓN. 2. LA REGULACIÓN LEGAL Y REgLAMENTARIA: A) Las transferencias a los Entes preautonómicos y a las Comunidades autónomas. B) Disposiciones legales y reglamentarias posconstitucionales: a) Las acciones legales de impugnación. b) El control directo por el Estado. c) La suspensión de acuerdos.-IV: LAS SENTENCIAS DEL TRIBUNAL CONSTITUCIONAL EN ORDEN AL TEMA: 1. LOS PRESUPUESTOS BÁSICOS. 2. INCIDENCIA DE LAS SENTENCIAS EN LA REGULACIÓN VIGENTE.-V. EL ACTUAL PROYECTO DE LEY DE BASES DE LA ADMINISTRACION LOCAL: 1. El CONTROL DE LEGALIDAD PROPIAMENTE DIC Ho. 2. OTRAS CUESTIONES RELACIONADAS CON EL CONTROL DE LEGALIDAD: A) Legislación estatal aplicable. B) Competencias compartidas. C) Competencias estatales.-VI CONCLUSIONES SOBRE EL ESTADO DE LA CUESTION EN GENERAL: 1. RESPECTO DE LAS COMUNIDADES AUTÓNOMAS. 2. RESPECTO DE LOS ENTES LOCALES. 


\section{INTRODUCCION}

España, a través de la Constitución aprobada por las Cortes en 31 de octubre de 1978, y refrendada nacionalmente el 6 de diciembre siguiente, ha establecido un cambio sustancial en su modelo de Estado. De un Estado centralizado, de acuerdo con el sistema napoleónico de Administración pública, acentuado por la concentración de poderes en el Jefe del Estado - la cual, a su vez, se refleja en los órganos del Gobierno central-; se ha pasado a un modelo de Estado que se ha dado en llamar «Estado de las Autonomías». Estas autonomías no son única y exclusivamente las de las Comunidades autónomas, sino también las de la Provincia y el Municipio, si bien aquéllas gozan de una descentralización no sólo administrativa, sino también política, sobre todo por su capacidad legislativa.

Es lógico que un cambio tan importante de conceptos lleve implícito un cambio fundamental en las formas y procedimientos. La Constitución y el nuevo modelo de Estado requieren de unas nuevas leyes estructurales que permitan su desarrollo y efectividad.

Si la autonomía es uno de los conceptos básicos en la nueva organización estatal, administrativa y social de España, la regulación de las Comunidades autónomas, Provincias y Municipios será fundamental para conseguirla. De otro lado, el gran problema reside en la necesidad de combinar este sentido autonómico de nuestra Constitución con el sentido, también constitucional, de la unidad de España. El sentido unitario de España radica precisamente en el concepto de Estado, y es el Estado el que ineludiblemente está encargado de fijarlo, controlarlo y desarrollarlo, de modo que se pueda seguir hablando de un Estado de las Autonomías y no de unos Estados autonómicos.

En este doble juego de respeto a la diversidad y libertad de autogobierno de los pueblos de España y de afirmación de su unidad, existe una técnica - quizá originariamente política y hoy jurídicoadministrativa - que se constituye en fundamental en el tema: el control de la legalidad de la actuación de los Entes autonómicos.

De otra parte, el control de legalidad es consecuencia inmediata del principio de legalidad de la actuación de las Administraciones públicas, y no sólo atribuible al Poder judicial o a los Tribunales, sino que tiene su manifestación de diversas formas dentro del seno 
de la Administración pública, bien a través de las técnicas de autocontrol o bien a través de la denominada «tutela» entre Administraciones públicas (1).

Es precisamente, pues, el control de legalidad por el Estado de la actuación de las Administraciones públicas con autonomía a nivel regional y local, sus antecedentes y perspectivas ante la nueva situación, el objeto de este estudio, en un intento más de explicación que de dogmatización.

\section{LA REGULACION ANTERIOR A LA CONSTITUCION DE 1978}

De lo expuesto en el punto anterior se deduce que el sistema preconstitucional suponía un régimen político y administrativo fuertemente centralizado, y naturalmente las concepciones de las relaciones entre las Administraciones citadas reflejaban y obedecían a esta estructura organizativa.

El texto que nos interesa preferentemente como reflejo de la situación anterior a la Constitución de 1978, y donde se establece claramente cuál era el sistema de relaciones entre la Administración central y local y los controles establecidos por la primera sobre la segunda, es el Texto articulado y refundido de las Leyes de Bases de Régimen local de 17 de julio de 1945 y 3 de diciembre de 1953, aprobado por Decreto de 24 de junio de 1955. Este texto ha seguido siendo básico hasta el momento actual, a pesar de la Ley 41/1975 de Bases del Estatuto de Régimen local, ya que ésta sólo se ha desarrollado parcialmente por el Real Decreto 3046, de 6 de octubre de 1977.

No es necesario explicar, por conocido, el régimen denominado como «tutela administrativa» y sus versiones de tutela sobre la actividad y tutela sobre la organización. Sí cabe, sin embargo, destacar que no hay por qué identificar el sistema como privativo de' determinados regímenes políticos, pues sus raíces se corresponden mejor como propias de un sistema concreto de organización: la cen-

(1) Garrido Falla: Administración indirecta del Estado y descentralización funcional, Madrid, Instituto de Estudios de Administración Local, 1950, págs. 176 y siguientes.

Baena del Alć́zar: Administración Central y Administración Institucional en el Derecho Español, Madrid, Instituto de Estudios Administrativos, 1976, págs. 119 y siguientes. 
tralización. La cuestión, fuera matices políticos, una vez determinado el modelo de Estado correspondiente, tiene carácter técnico y organizativo, y, finalmente, el tema supone también una cuestión de competencias entre Administraciones públicas (2).

El control sobre la actividad de unas organizaciones sobre otras es el nexo o pasillo de unión entre sus diferentes esferas de competencias. Sea cual sea la unidad que se escoja como base y su extensión, la técnica de la organización lleva a la existencia de controles que mantengan el sentido y el espíritu unitario.

También es necesario destacar cómo, de acuerdo con el criterio que Alejandro de OlivíN mantenía en su obra De la Administración pública con relación a España, el Alcalde asumía el doble papel de Jefe de la Administración municipal y de representante del Poder o Administración central en el Municipio. En el caso del Presidente de la Diputación este doble papel no entraba en juego ante la presencia del Gobernador civil, órgano central con sede provincial, salvo en la posibilidad de suspensión de acuerdos de las Corporaciones locales que la ley asignaba a sus Presidentes (3).

Respecto a la tutela sobre la actividad, dejando aparte la vía de los recursos posibles ante el órgano tutelar, el control más característico en la Ley de Régimen local era el de la suspensión de los acuerdos de éstos y aquéllas por el Gobernador civil. Así pues, dos autoridades podían suspender los acuerdos de las Corporaciones locales: sus Presidentes, y ello como representantes del Poder central, y los Gobernadores civiles, en los casos y formas establecidos por los artículos 362 y siguientes de la Ley de Régimen local. La suspensión procedía en casos de incompetencia, delito, contrariedad al orden público e infracción manifiesta de las leyes.

Cuando la suspensión era acordada por los Presidentes de las Corporaciones, en los tres primeros casos necesitaba de la ratificación expresa o tácita del Gobernador o, en caso contrario, procedía la revocación expresa. Contra estas resoluciones cabía recurso de alzada. Sin embargo, en los casos de suspensión por infracción manifiesta de las leyes, los Presidentes de las Corporaciones locales o los Gobernadores civiles debian dar traslado de la suspensión a la

(2) Fernández Rodríguez, Tomás-Ramón: «El sistema de distribución de competencias entre el Estado y las Comunidades Autónomas», RevisTA DE ESTUdios DE LA VIDA LocAl, núm. 201, enero-marzo 1979, págs. 9 y sigs.

(3) Olrván, Alejandro de: De la Administración pública con relación a España, Madrid, Instituto de Estudios Políticos, 1954. 
Sala de lo Contencioso de la Audiencia Territorial, conforme al procedimiento especial establecido en los artículos 118 y siguientes de la Ley de la Jurisdicción Contencioso-administrativa. En definitiva, pues, en los tres primeros casos, acordada la suspensión, era preciso agotar la vía administrativa, mientras que en el caso de infracción manifiesta de las leyes la intervención judicial era directa, prácticamente (4).

No obstante, muchos de los supuestos que pudieran encajar en los tres primeros casos del artículo 362 de la Ley de Régimen local, incompetencia, delito y ser contrarios al orden público, podían ser considerados como infracción manifiẹsta de la ley.

El artículo 13 del Estatuto de Gobernadores civiles de 10 de octubre de 1958 atribuía a los mismos la tutela e inspección de las Corporaciones, Asociaciones o Instituciones de carácter público.

En todo el sistema, el Gobernador civil, representante del Poder central, jugaba un papel importante en la suspensión, unas veces con carácter subsidiario de la acción de los Presidentes de las Corporaciones locales, y otras directamente, controlando los actos de éstos.

\section{LA REGULACION A PARTIR DE LA CONSTITUCION DE 1978}

En el transcurso de nuestra exposición se ha puesto de manifiesto el cambio sustancial que la vigente Constitución ha supuesto en el modelo de Estado y también hemos afirmado que el tema de los controles de unas Administraciones sobre otras deviene en una cuestión técnica y organizativa y en una clara cuestión de competencias.

Aun cuando posteriormente expondremos la jurisprudencia que en este terreno ha ido vertiendo hasta la fecha el Tribunal Constitucional, veremos ahora, y en primer lugar, si la Constitución de 1978 se opone o prohibe la existencia de controles por parte del Estado o de su Administración sobre las Administraciones territoriales.

(4) Boquera Oliver, José-Maria: «La facultad gubernativa de suspensión e impugnación de acuerdos locales manifiestamente ilegales», Revista de Administración Pública, núm. 36 (1961), págs. 109 y sigs. 


\section{La cuestión en la Constitución}

Del examen de la Constitución no se deduce ningún precepto expreso de carácter negativo o prohibitorio; únicamente hay una afirmación de autonomía y autogobierno de las Comunidades autónomas y de la Provincia y Municipio. El problema, pues, debe analizarse desde el punto de vista de los límites a estas autonomías y a la luz de los preceptos constitucionales.

Los primeros límites vienen marcados en el Título preliminar de la Constitución, y concretamente en sus artículos $2 .^{\circ}$ y $9 .^{\circ}$ El primero, en cuanto dice: «La Constitución española se fundamenta en la indisoluble unidad de la Nación española, Patria común e indivisible de todos los españoles, y reconoce y garantiza el derecho a la autonomía de las Nacionalidades y Regiones que la integran y la solidaridad de todas ellas». El segundo, en cuanto establece en su párrafo $1 .^{\circ}$ la sujeción de los poderes públicos a la Constitución y al resto del Ordenamiento jurídico; en su párrafo $2 .^{\circ}$ atribuye a los Poderes públicos la promoción de las condiciones para la libertad e igualdad del individuo y los grupos en que se integra sean reales y efectivas, así como la remoción de los obstáculos que impidan o dificulten su plenitud; por último, en su párrafo $3 .^{\circ}$, garantiza el principio de legalidad, la jerarquía normativa, la seguridad jurídica y la responsabilidad e interdicción de la arbitrariedad de los Poderes públicos.

En resumen: unidad de España y solidaridad de las Autonomías; sometimiento a la Constitución y el Derecho como principio de legalidad; igualdad real y efectiva de individuos y grupos, y seguridad jurídica e interdicción de arbitrariedades, son los primeros límites a la autonomía de las Administraciones territoriales.

Estas limitaciones a las Autonomías, en contrapartida, se constituyen en competencias e incluso en obligaciones del Estado, naturalmente, a través del Gobierno y de la Administración estatal, que deben de velar por su cumplimiento y efectividad.

De otros artículos de la Constitución, pese a la no muy afortunada utilización constitucional del concepto de Administración pública, y en tanto se concretan a través de las leyes las competencias estatales, ya se deduce que al Gobierno le corresponde la política interior y la defensa del Estado -término este último que hay que interpretar en sentido amplio- (art. 97). La Administración 
pública sirve a los intereses generales y actúa, entre otros, de acuerdo con el principio de coordinación con sometimiento pleno a la Ley y al Derecho (art. 103); también este artículo hay que interpretarlo en sentido amplio y no entender por Administración pública únicamente la estatal; por ello el sometimiento a la Ley y al Derecho afecta a todas las Administraciones públicas, en concordancia con lo establecido por el artículo 9. Sin embargo, del artículo 103 cabe deducir que a la Administración estatal le corresponden la defensa del interés general y funciones de coordinación con las restantes Administraciones.

Ya en orden a la organización territorial, los artículos 138 y 139 insisten en el principio de solidaridad de las Autonomías y en la igualdad de derechos y obligaciones de todos los españoles. En el capítulo destinado a las Comunidades autónomas, aparte del deslinde de competencias de los artículos 148 y 149 y declaración de prevalencia de las normas estatales sobre las Autonomías en caso de conflicto (art. 149, 3), se establecen una serie de controles del Estado sobre las Comunidades autónomas, tales como: el control sobre facultades transferidas o delegadas (arts. 150, 2 y 3, y 153 , a), la coordinación por un Delegado del Gobierno en la Administración autónoma, entre uno y otra (art. 154), y, por último, el posible recurso de inconstitucionalidad sobre leyes, disposiciones y actos con fuerza de ley de las Comunidades autónomas y la impugnación por el Gobierno ante el Tribunal Constitucional de las disposiciones y resoluciones adoptadas por aquéllas; impugnación que produce la suspensión automática de la resolución (art. 161).

No se mencionan taxativamente controles sobre la Provincia y el Municipio; pero si en orden a las Comunidades autónomas vemos que caben los controles citados, hay que llegar a la conclusión, conforme a todo lo antedicho, que, en principio, el control de legalidad sobre las Entidades locales no es inconstitucional. Como decíamos antes, el problema es de competencias y, por tanto, de los límites existentes entre éstas. Frente a los límites expresados con anterioridad, el artículo 137 fija el límite básico de las Autonomías: el de sus respectivos intereses. El artículo dice literalmente: «El Estado se organiza territorialmente en Municipios, en Provincias y en las Comunidades autónomas que se constituyan. Todas estas Entidades gozan de autonomía para la gestión de sus respectivos intereses". 
De este modo la Constitución ya fija unas competencias del Estado de carácter general y limita las de los Entes con autonomía a la esfera de sus intereses propios.

Veremos ahora cuál ha sido el desarrollo legal y reglamentario de los sectores que afectan al tema del control de legalidad de la actividad de los Entes territoriales.

\section{LA REGULACIÓN LEGAL Y REGLAMENTARIA}

Todos estos principios generales y amplios que establece la Constitución son normas básicas que han de tenerse en cuenta en la estructuración orgánica y administrativa del nuevo Estado y de las Comunidades autónomas, así como de la Administración provincial y municipal.

El tiempo transcurrido desde la aprobación de la vigente Constitución y algunas normas legales y reglamentarias posteriores a. la misma, nos permiten perfilar cómo los mencionados principios se van desarrollando y, concretamente, nos facilitan los rasgos esenciales que conforman la situación actual del tema del control de legalidad de los actos de los Entes territoriales y aún más concretamente de la suspensión de los mismos por el Estado.

\section{A) Las transferencias a los Entes preautonómicos y a las Comunidades autónomas}

Aun antes de la aprobación de la Constitución, las transferencias de competencias y funciones a los Entes preautonómicos, que se inician con el Real Decreto 2115/1978, de 26 de julio, respecto de la Administración a la Generalidad de Cataluña, constituyen el primer indicio sobre la cuestión que nos ocupa.

Efectivamente, a través de este Real Decreto, y todos los que posteriormente se han referido a otros Entes preautonómicos y Comunidades autónomas, se han transferido las facultades de suspensión de acuerdos de las Corporaciones locales en los supuestos contemplados en los apartados 1, 2 y 4 del artículo 362 de la Ley de Régimen local.

Estos apartados permitían la suspensión de los acuerdos municipales o provinciales por los Presidentes de las Corporaciones locales en los casos de incompetencia, delito e infracción manifiesta de las leyes. No se transfieren, en cambio, las competencias que 
este mismo artículo confería en cuanto a la suspensión de acuerdos contrarios al orden público.

La normativa de las transferencias es confusa por las siguientes razones:

a) Las competencias de los Presidentes de las Corporaciones locales de suspensión de los acuerdos de éstas eran competencias que se ejercían en su papel de Delegado del Gobierno, y la posibilidad de que hubieran podido o puedan seguir ejerciéndolas no es inconstitucional, como la propia sentencia del Tribunal Constitucional del 2 de febrero de 1981 reconoce en uno de sus Considerandos.

b) Las competencias de los Entes preautonómicos son transferidas, no delegadas, y no se concreta en la esfera de qué intereses se efectúa la transferencia. Es decir, no se concreta por la norma si las competencias transferidas del artículo 362 lo son en la esfera de intereses de la Comunidad autónoma. Esto sería lo lógico, dado que, como hemos dicho, hay una transferencia y no una delegación, y ello daría congruencia al sistema, tal como veremos queda delimitado finalmente.

c) El Estado se reserva la facultad para suspender acuerdos en cuanto no lo haga la Comunidad autónoma o Ente preautonómico.

Sigue la confusión al no estar delimitada la esfera de los intereses afectados por los actos administrativos de las Corporaciones locales.

¿Puede suspender el Estado actos manifiestamente ilegales que afecten únicamente a los intereses de un Municipio, Provincia o Comunidad autónoma? Hasta la publicación del Real Decreto-ley 3/1981, que luego analizaremos, hay que llegar a la conclusión de que el Estado podía suspender cuando no lo hacía el Ente preautonómico o la Comunidad, si estaba constituida.

d) Las competencias de suspensión de acuerdos contrarios al orden público del artículo 362, al no estar transferidas, hay que entenderlas persistentes en los Presidentes de las Corporaciones locales y en el Gobernador civil.

En definitiva, los acuerdos de las Corporaciones locales pueden ser suspendidos por los Entes preautonómicos o las Comunidades autónomas en los casos siguientes: 1) cuando recaigan en asuntos que según las leyes no son de su competencia; 2) cuando constitu- 
yan delito, y 3) cuando constituyan infracción manifiesta de las leyes.

Nada se dice en la transferencia sobre el procedimiento y no se indica qué órgano del Ente preautonómico o Comunidad tiene la competencia de suspensión atribuida, y, como ya hemos indicado, no se concreta si la competencia se limita al campo de intereses del Ente o Comunidad. Como no se distinguía, cabía entender que la Comunidad autónoma podía suspender acuerdos tomados en materias de competencia estatal, en virtud de la transferencia.

Esta posición concuerda con alguna interpretación dada al artículo 148, 1, 2. ${ }^{a}$, de la Constitución, que dice que las Comunidades autónomas podrán asumir, en general, las funciones que corresponden a la Administración del Estado sobre las Corporaciones locales y cuya transferencia autorice la legislación sobre Régimen local.

El Estado veremos que ha jugado después con este condicionamiento.

Respecto a estas transferencias de competencias del artículo 362 de la Ley de Régimen local, sólo queda un tema por dilucidar, y es el siguiente: ¿cómo quedan las facultades del Gobernador civil para suspender los actos de los Presidentes de las Corporaciones locales en los casos en que incurran en los supuestos del citado artículo 362 ?

Lógicamente, al transferirse la competencia, desaparecen. ¿Cabe, sin embargo, entender que esta misma facultad le queda atribuida respecto de los Entes preautonómicos o Comunidades autónomas? A la vista del artículo 161, 2, de la Constitución y de las disposiciones que a continuación examinaremos, cabe concluir que esta posibilidad no existe y que sólo cabe la impugnación ante el Tribunal Constitucional o Tribunales ordinarios.

\section{B) Disposiciones legales y reglamentarias posconstitucionales}

El camino emprendido por las transferencias antes de la aprobación de la Constitución, respecto a Cataluña y Vascongadas, ha seguido siendo el mismo después de promulgada y refrendada ésta, en lo que afecta a los restantes Entes preautonómicos, pero una serie de leyes y disposiciones posteriores han ido concretando la cuestión de modo que el tema de la suspensión de acuerdos de 
los Entes territoriales por el Estado, y el más amplio del control de legalidad, queda situado con mayor claridad.

Estas normas se refieren a las Comunidades autónomas y son, principalmente, la Ley Orgánica del Tribunal Constitucional, de fecha 3 de octubre de 1979, y el Real Decreto de 10 de octubre de 1980, sobre la actuación de los Delegados del Gobierno en las Comunidades autónomas. Otras afectan al campo de la Administración local, en su doble esfera provincial y municipal, y son: el Real Decreto-ley 3/1981, de 16 de enero, sobre Régimen jurídico de las Corporaciones locales, y el Real Decreto de 22 de diciembre de 1980, que aprueba el Estatuto de los Gobernadores civiles. El Real Decreto-ley 3/1981 : ha sido derogado por la Ley 40/1981, de 28 de octubre, de casi idéntico contenido, pero que introduce una novedad sobre aquél de carácter definitivo en el tema.

Estas cinco normas permiten conocer las funciones o competencias que los órganos representantes del Poder central o de la Administración general en los Entes territoriales - Comunidad autónoma, Provincia y Municipio- pueden ejercer en orden a los mismos.

En líneas generales, los Reales Decretos reguladores de los Gobernadores civiles y Delegados del Gobierno destacan dos aspectos en las funciones de estos órganos: a) su carácter de Jefes de los Servicios de la Administración central en el ámbito territorial correspondiente; y $b$ ) su carácter de Delegados del Gobierno en el Ente territorial autonómico o provincial.

Conviene, en orden al tema objeto de este trabajo, examinar el segundo aspecto, $\mathrm{y}$, en este orden, hay que destacar que a esos órganos gubernamentales se les encomienda con carácter general el velar por el cumplimiento de las leyes y reglamentos del Estado, así como de los acuerdos y resoluciones de la Administración del Estado en el territorio correspondiente.

Consecuencia de esta atribución genérica, surgen otras competencias más concretas que van desde las tareas de impulso y fomento de actividades, informes y propuestas al Gobierno de acciones, inversiones y colaboraciones en o con los Entes territoriales, hasta las funciones que podemos denominar de control de la actividad de los citados Entes respecto del cumplimiento de la legalidad y de la Constitución. 


\section{a) Las acciones legales de impugnación}

Las cinco normas citadas incluyen sistemas o acciones que el Gobierno o sus representantes pueden ejercer respecto de los actos de los Entes territoriales que consideren ilegales o inconstitucionales.

Así, la Ley Orgánica del Tribunal Constitucional, en sus artículos 76 y 77, desarrolla el artículo 161, 2, de la Constitución y faculta la impugnación ante dicho Tribunal de las disposiciones normativas sin fuerza de ley y resoluciones emanadas de cualquier órgano de las Comunidades autónomas. Sea cual fuere el motivo de la impugnación, ésta se sustancia por el procedimiento establecido para la resolución de los conflictos positivos entre el Estado y las Comunidades autónomas. La impugnación produce la suspensión de la disposición, hasta que el Tribunal Constitucional ratifique o levante dicha suspensión.

La Constitución y la Ley Orgánica son claras: las disposiciones sin fuerza de ley y los acuerdos o actos de las Comunidades autónomas son impugnables ante el Tribunal Constitucional. La suspensión de la norma o acto no es, en este caso, una competencia estatal, sino un imperativo constitucional y legal que puede levantar el Tribunal.

Sin embargo, el Real Decreto de 10 de octubre de 1980, sobre los Delegados del Gobierno, introduce una variante, y en su artículo $7 .^{\circ}, 2$, no sólo faculta al Delegado a informar al Gobierno respecto al ejercicio de la acción impugnatoria del artículo 161, 2, de la Constitución, y que, hemos visto, desarrolla la Ley Orgánica del Tribunal, sino que permite que el mencionado Delegado del Gobierno promueva, si procede, el ejercicio de las acciones legales que puedan corresponder a la Administración del Estado ante los Tribunales ordinarios, contra los acuerdos y disposiciones normativas de rango inferior a la ley emanadas por los órganos de la Comunidad autónoma.

Esta disposición y la Ley 34/1981, que más adelante citamos, supone, en definitiva, el establecimiento de una doble vía de impugnación de los acuerdos y disposiciones normativas de rango inferior a la ley, dictadas por las Comunidades autónomas: la vía ante la Jurisdicción ordinaria y contencioso-administrativa y la vía ante el Tribunal Constitucional. En ningún momento queda claramente establecido cuándo procede una u otra, o si ambas son indistintas 
en su elección. Parece un intento de descargar al Tribunal Constitucional de la tarea que le atribuye el artículo 161, 2, de la Constitución, y al establecer que la acción de impugnación prevista en este artículo corresponde al Gobierno, el Real Decreto nos ofrece una especie de interpretación del citado artículo constitucional, a través de la cual se previera la impugnación de las citadas normas y acuerdos ante el Tribunal Constitucional, sólo cuando se basara en motivos de inconstitucionalidad.

De este modo, en los restantes casos, la impugnación correspondería al Delegado del Gobierno y ante los Tribunales ordinarios o contencioso-administrativos, según los casos.

Esta interpretación que parece pretender el Real Decreto choca, sin embargo, con el hecho de que el artículo 161, 2, de la Constitución no distingue, y con el de que la Ley Orgánica del Tribunal Constitucional, en su artículo 77, admite cualquier motivo de impugnación cuando dice que ésta se sustanciará por el procedimiento de los conflictos positivos entre el Estado y las Comunidades autónomas. En definitiva, el Real Decreto ha introducido la confusión en este campo concreto, si bien su solución sea la más lógica.

La Ley $40 / 1981$, de 28 de octubre, en su artículo $9 .^{\circ}$, legitima a la Administración del Estado para impugnar los acuerdos de las Corporaciones locales que infrinjan el Ordenamiento jurídico.

En el mismo orden de ejercicio de acciones legales, el nuevo Estatuto de Gobernadores civiles atribuye a los mismos la promoción de la interposición de recursos y el ejercicio de las acciones correspondientes en defensa de la Constitución y el Ordenamiento jurídico, así como el promover cuestiones de competencias y suscitar conflictos de atribuciones, de acuerdo con las previsiones legales (artículos 11 y 16), naturalmente en el campo de la Administración local.

En resumen, podemos concluir que una de las primeras manifestaciones del control de legalidad de la actividad de los Entes territoriales por el Estado, y consecuencia de su obligación de velar por la Constitución y el Ordenamiento jurídico, es el ejercicio de las acciones legales ante los Tribunales correspondientes, según los casos, y con ello concretamos una competencia estatal y, consecuentemente, de sus órganos representativos, Gobierno, Delegados en las Comunidades autónomas y Gobernadores civiles. En concreción de estas acciones, la Ley 34/1981, de 5 de octubre, establece 
que la Administración del Estado estará legitimada para recurrir, ante la Jurisdicción contencioso-administrativa, las disposiciones generales y actos emanados de la Administración de las Comunidades autónomas y Entidades sujetas a la tutela de éstas.

\section{b) El control directo por el Estado}

Otra competencia, y al mismo tiempo forma de control, se deduce de la Constitución y del Real Decreto de 10 de octubre de 1980, sobre actuaciones de los Delegados del Gobierno en las Comunidades autónomas, y es el ejercicio por los órganos de las Comunidades autónomas de las funciones delegadas, conforme a lo dispuesto en el artículo 150 de la Constitución (arts. 153 de la Constitución y $7 .^{\circ}, 2$, del Real Decreto de 10 de octubre de 1980), cuyo control se reserva el Estado, aun cuando no se ha establecido con carácter general un sistema de control. Unicamente ante algunas transferencias el Estado se ha reservado algunas facultades de aprobación.

Dentro de este campo, que hemos titulado control directo, cabe incluir la posibilidad de adopción, por parte del Gobierno, de las medidas necesarias para obligar a las Comunidades autónomas a cumplir con sus obligaciones, en caso de que no lo hagan en los términos previstos en el artículo 155 de la Constitución.

En este orden, el Delegado del Gobierno en la Comunidad es competente para informar al Gobierno respecto del ejercicio de esta facultad (art. 7. del Real Decreto de 10 de octubre de 1980). Sin embargo, el sistema que establece el artículo 155 de la Constitución va más allá de un simple control gubernamental o administrativo, tiene claras implicaciones políticas y requiere la intervención del Senado.

\section{c) La suspensión de acuerdos}

Hasta ahora, del examen de la legislación y reglamentación anterior no se ha deducido claramente la posibilidad de suspensión de acuerdos de los Entes territoriales por parte del Estado. De las transferencias de competencias hemos llegado a la conclusión de que no cabe la suspensión automática de los acuerdos de los Entes preautonómicos o de las Comunidades autónomas; esta suspensión sólo se producía a través de la impugnación prevista en el artícu- 
lo 161,2 , de la Constitución y en los 76 y 77 de la Ley Orgánica de! Tribunal Constitucional.

Sí cabía, sin embargo, la suspensión directa por el Gobernador civil de los acuerdos de las Corporaciones locales o sus Presidentes por contrarios al orden público, según el apartado 3 del artículo 362 y el artículo 364 de la Ley de Régimen local. Igualmente cabía la suspensión por el Gobernador civil cuando el Ente preautonómico o la Comunidad autónoma no hiciesen uso de la facultad de suspensión prevista en los números 1, 2 y 4 del artículo 362 de la Ley de Régimen local y a ellos transferida.

El Real Decreto-ley 3/1981, de 16 de enero, regulaba el Régimen jurídico de las Corporaciones locales y se ocupaba del tema de la suspensión de acuerdos de las Corporaciones locales por el Gobierno, en su artículo $8 .^{\circ}$, que exigía la doble concurrencia siguiente:

a) Que dichos acuerdos afecten a materias competencia del Estado; y

b) Que constituyan infracción de las leyes.

Prescindiendo de que, en cierto modo, la doble exigencia no es tal, ya que si el acuerdo afecta a materias que no son de competencia provincial o municipal e incurre, por tanto, en incompetencia lo normal es que se incurra en ilegalidad, lo importante es que el artículo ya no centra la suspensión como una cuestión única del Estado, y es este factor el que da el nuevo sentido al tema de la suspensión de acuerdos de las Corporaciones locales y, al mismo tiempo, señala cuál debe ser el camino respecto a las Comunidades autónomas y el control de legalidad de su actuación por el Estado y también el del control de legalidad de las Corporaciones locales por aquéllas.

La Ley 40/1981, de 28 de octubre, que viene a sustituir al Real Decreto-ley mencionado, introduce, sin embargo, una variante importante en el citado artículo $8 .^{\circ}:$ deja de mencionar el término "suspensión de acuerdo" y dice que los actos de las Corporaciones locales en los que se dé la concurrencia ya señalada "podrán ser impugnados» por la Administración del Estado ante la Jurisdicción contencioso-administrativa. Dicha impugnación produce la suspensión del acto, que puede ser levantada o mantenida por el Tribunal ren un plazo no superior a treinta días. Luego la suspensión es 
causa de la ley y no un acto de la Administración del Estado. El plazo de ejercicio de la acción de impugnación es, sin embargo, de seis días, más breve, por lo tanto, que los plazos normales de la ley, y ello porque el procedimiento sigue siendo el del artículo 118 de la LJCA, antes establecido para la suspensión.

Aunque la Ley no dice qué órgano impugna los acuerdos, se deduce que esta facultad respecto de las Corporaciones locales corresponde al Gobernador al concretar un Real Decreto de 5 de febrero siguiente al Real Decreto-ley 3/1981, los órganos a los que los Entes locales deben remitir sus acuerdos.

Lo que sí, definitivamente, suponía el Real Decreto-ley, y supone la Ley sensu contrario, es una limitación de la transferencia de las facultades de suspensión a los Entes preautonómicos y Comunidades autónomas a la esfera de sus competencias. La cuestión, según puntos de vista, puede estimarse una reconsideración o marcha atrás, o una precisión de lo que era evidente.

La primera posición coincide con la de aquellos que, como anteriormente decíamos, consideran transferidas las funciones de control del Estado sobre las Corporaciones locales a los Entes preautonómicos y Comunidades autónomas. Lo cierto, sin embargo, es que las competencias transferidas en este orden de control eran las del 362 de la Ley de Régimen local, cuyo sistema, por mor de la Constitución, se convirtió en inadecuado respecto de las autonomías locales, con lo que la competencia transferida habría sufrido modificaciones de fondo y forma, y por ello la transferencia debe entenderse no procedente en lo que la Constitución deroga $\mathrm{y}$, por tanto, nula. Ello implica que el Decreto-ley 3/1981, de 16 de enero, modificó la competencia del Estado y que la Ley de Régimen local que se apruebe es la que determinará las funciones o competencias que se deleguen en las Comunidades autónomas. La Ley 40/ 1981 mantiene la situación, y la conclusión debe ser la misma.

Sí queda claro que el Estado para suspender debe seguir el camino marcado por el artículo 118 de la LJCA. No queda tanto respecto al sistema de suspensión de acuerdos de las Corporaciones locales por las Comunidades autónomas, que a la luz de las transferencias y Ley de Régimen local queda así:

a) Apartados 1 y 2 del artículo 362 de la Ley de Régimen local: cabe la suspensión directa.

b) Apartado 4, artículo 362, de la Ley de Régimen local: el procedimiento del artículo 118 de la LJCA. 
La posibilidad de esa suspensión directa no parece estimarla procedente, pues es tan atentatoria a la autonomía local como se pretende lo es el mismo control del Estado sobre las Comunidades autónomas, por lo que en estos casos cabe considerar que sería procedente seguir la vía del 118 de la LJCA y el mismo criterio que la reciente Ley 40/1981 mantiene para el Estado. Estas cuestiones evidencian la precipitación que han supuesto las transferencias y los problemas que han planteado y la falta de coordinación en las leyes.

\section{LAS SENTENCIAS DEL TRIBUNAL CONSTITUCIONAL EN ORDEN AL TEMA}

Dos sentencias del Tribunal Constitucional se han ocupado de la cuestión del control de legalidad de la Administración del Estado, preferentemente en el orden de la Administración local; una, la Ley citada, de 2 de febrero de 1981, recurso número 186/80, y la segunda, de 29 de abril de 1981, cuestión de inconstitucionalidad, número $17 / 1981$. La primera de ellas, extensa, ya que el recurso planteado impugnaba una buena serie de preceptos de las Leyes de Bases de Régimen local de 1945 y 1953, así como de la de 1975, por inconstitucionales y contrarios al principio de autonomía de los Entes locales.

Interesa aquí destacar la doctrina básica contenida en las sentencias y no el análisis pormenorizado de los razonamientos o pronunciamientos en torno a cada precepto recurrido.

\section{LOS PRESUPUESTOS BÁSICOS}

Al inicio de este trabajo señalamos una serie de preceptos de la Constitución que entendíamos constituían límites a la autonomía de los Entes territoriales, y en ocasiones hemos resaltado que en el fondo de la cuestión existe un problema de competencias. La sentencia de 2 de febrero de 1981 se desenvuelve precisamente en este terreno, y en él fija las líneas generales en las que el control de legalidad de unas Administraciones sobre otras pueden desarrollarse.

Previamente, la sentencia, y aun cuando referida al establecimiento de los límites en los que pueden plantearse las distintas opciones políticas, realiza la afirmación de que el principio de au- 
tonomía de Municipios y Provincias se traduce en que la función del Tribunal consiste en fijar unos límites cuya inobservancia constituiría una negación de principio de autonomía, pero dentro de las cuales las diversas opciones pueden moverse libremente. Aun cuando, como decíamos, preocupada por el principio de pluralidad política y la autonomía, esta afirmación sensu contrario hace pensar que esos mismos límites, cuya inobservancia niega el principio de autonomía, van a servir para limitar el terreno en que la autonomía debe desenvolverse para no negar el principio de unidad ni el concepto de Estado.

Por ello, la siguiente declaración del Tribunal entra, ya de lleno, en el principio inicial de la Constitución que establece (art. 2..$^{\circ}$ ) la unidad de la Nación española y la organización que la traduce: el Estado; si bien resaltando cómo el poder público no es ejercido en su totalidad por los órganos generales del Estado, ya que de acuerdo con una distribución vertical de poderes, las Entidades territoriales participan en este ejercicio, conforme a lo expresado en el artículo 137 de la Constitución, al fijar la organización territorial del Estado en Municipios, en Provincias y en las Comunidades autónomas, que gozan de autonomía para la gestión de sus propios intereses.

Deseo, aunque incidentalmente, destacar cómo en esta afirmación jurisprudencial se acude a calificar a los órganos del Estado como órganos generales, desechando la expresión hasta ahora utilizada de órganos centrales, lo que supone una vuelta a un concepto de Administración general, ya recogido en Alejandro de Oliván, y aúna con un carácter más firme el concepto de Administración del Estado como un todo que extiende sus competencias al territorio nacional en toda su extensión (5).

Sentado el concepto de unidad y la concepción constitucional de carácter amplio del Estado, el siguiente paso de la sentencia, totalmente congruente, es fijar los límites de la autonomía, y, así, afirma que ésta hace referencia a un poder limitado, que no es soberanía, y que las organizaciones territoriales son la parte de un todo. Estos conceptos coinciden básicamente con los que ya imperaban en las leyes del régimen franquista y, por tanto, conviene

(5) Oliván, Alejandro de: Op. cit., pág. 153. 
poner de relieve que aun cuando obedezcan a principios políticos en su inicio, constituyen hoy unos principios científicos de organización que devienen jurídicos al ser recogidos por la norma. Se utilizan tanto en un régimen democrático como en el que no lo es, porque sólo hacen que reflejar el concepto de Estado, prescindiendo de su organización.

En la fijación de los límites de la autonomía la sentencia incide en que los Entes territoriales reconocidos por el artículo 137 se organizan para la "gestión de sus propios intereses", y, conforme a lo que ya hemos destacado con anterioridad, llega a la conclusión de que para ello es necesario dotar a estos Entes de todas las competencias propias y exclusivas que sean necesarias para el cumplimiento de este fin. Tema que enlaza con la posibilidad de existencia de las denominadas competencias compartidas y de las exclusivas, y que en la esfera local se pueden presentar frente, o junto, al Estado y las Comunidades autónomas. El punto neurálgico que se presenta siempre en la cuestión es, repetimos una vez más, un tema de competencias que, pese a su concreción en las leyes, estará siempre enumerado con carácter general por el Ordenamiento jurídico total y que en el caso de concurrencia de intereses, por consiguiente de competencias compartidas, sólo puede resolverse en atención a la preferencia de los intereses generales sobre los particulares, en una gradación conforme con la mayor o menor amplitud del ámbito territorial de referencia.

Por ello la sentencia dice literalmente, refiriéndose a la Constitución, lo siguiente: "Y debe hacerse notar que la misma contempla la necesidad - como una concurrencia del principio de unidad y de la supremacía del interés de la Nación- de que el Estado quede colocado en una posición de superioridad, tal y como establecen diversos preceptos de la Constitución, tanto en relación a las Comunidades autónomas, concebidas como Entes dotados de autonomía cualitativamente superior a la administrativa (arts. 150, 3, y 155, 3, 543 y otros), como a los Entes locales (art. 148, 12)».

Basándose en esta superioridad, la sentencia afirma que el principio de autonomía es compatible con la existencia de un control de legalidad sobre el ejercicio de las competencias y en evitación de que este control se establezca de forma genérica e inconcreta que suponga, en definitiva, no una superioridad, sino una jerarquización entre Administraciones, la sentencia dice que: «en todo caso, 
los controles de carácter puntual habrán de referirse normalmente a supuestos en que el ejercicio de las competencias de la Entidad local incida en intereses generales concurrentes con los propios de la Entidad, sean del Municipio, la Provincia, la Comunidad autónoma o el Estado".

Esta es, en esencia, la secuencia lógica del Tribunal Constitucional para declarar constitucional el control de legalidad y su ejercicio por el Estado y las Comunidades autónomas sobre los Entes locales, provinciales y municipales, y de aquél sobre las Comunidades, así como para encuadrarlo en los límites de interés y competencias ya referidos.

Existe otra sentencia de 29 de abril de 1981 en cuestión de inconstitucionalidad, promovida por una Sala de lo Contencioso-administrativo, respecto de la suspensión de un acuerdo municipal por el Gobernador civil, conforme a los artículos 365, 1, y 362, 1, $4 .^{\circ}$, de la Ley de Régimen local, por infringir manifiestamente el artículo 294, 3, de la citada Ley, y el 192 de su Reglamento de Organización, Funcionamiento y Régimen jurídico de las Corporaciones locales, que inciden en la cuestión.

Para centrar el tema de un modo más completo hay que reseñar que el artículo 294, 3, de la Ley de Régimen local se refiere a que la convocatoria de las sesiones extraordinarias deberá hacerse con dos días de antelación al menos, salvo casos de urgencia, y será motivada, expresando los asuntos a que se han de circunscribir las deliberaciones y los acuerdos, sin que puedan tratarse otros asuntos.

En este caso, la sentencia declara en su sexto fundamento jurídico que la suspensión gubernativa de acuerdos municipales sin otra razón que el control de legalidad en materia que corresponda al ámbito competencial exclusivo de las Entidades locales, no es compatible con la autonomía que hoy proclama el artículo 137 de la Constitución, porque entraña una tutela sin otro fundamento que la defensa de la legalidad ejercitable por una vía excepcional. Más adelante continúa diciendo: «... la excepción que a la ejecutoriedad de los actos locales supone la suspensión, deja en manos de la autoridad gubernativa un medio excesivamente restrictivo de la actuación local en la gestión de sus propios intereses. Por el contrario, la suspensión en cuanto sirva a la defensa de competencias del Estado u obedezca a corregir invasiones de ámbitos ajenos al municipal o se afecte a materia que corresponde a aquella Admi- 
nistración, no podrá decirse que entraña un atentado a la autonomía local, entendida como ámbito de actuación propia que tiene sus límites».

Consecuentemente, el fallo declara que el artículo 365,1 , en relación con el artículo $362,1,4^{\circ}$, de la Ley de Régimen local, Texto refundido de 1955, no se ajusta a la Constitución en la parte que permite que la facultad de suspensión de los acuerdos de las Corporaciones locales proceda por la sola infracción manifiesta de las leyes, sin la concurrencia de otra circunstancia, pero sí se ajusta a la Constitución interpretado en el sentido de que confiere una facultad gubernativa para suspender acuerdos que afectan a la competencia del Estado o exceden del límite de la competencia propia para la gestión de los intereses de la Entidad local.

El caso concreto de esta sentencia, suspensión de un acuerdo por infracción de unos requisitos formales en la convocatoria de una sesión extraordinaria de una Corporación local, de acuerdo con lo exigido en un precepto legal, nos puede servir para ver cómo la cuestión de las competencias e intereses están íntimamente relacionadas.

En una interpretación amplia del concepto competencia del Estado, cualquier acuerdo municipal que quebrante un precepto de ley estatal establece una excepción legal que no le corresponde. Este acuerdo puede producirse, por ejemplo, de dos formas:

$1 .^{a}$ Estableciendo con carácter general que las sesiones extraordinarias del Municipio se regirán de forma distinta a la señalada por la ley, en cuyo caso la invasión, por excepción o modificación, de una competencia del Estado ejercitable a través del Parlamento es clara, pese a que sea en contenido de procedimiento y en aspectos formales.

2. Convocando la sesión extraordinaria sin atender a los requisitos legales formales exigidos, lo que supone claramente una infracción de ley, pero sin embargo la voluntad de invadir un terreno o unas competencias que no le corresponden no queda tan clara como en el supuesto anterior. El quebranto de intereses generales no es manifiesto.

El ejemplo permite concretar cómo los intereses quebrantados tienen clara importancia y cómo la interpretación con carácter genérico de la cuestión es difícil; pero las líneas generales de la doctrina jurisprudencial constitucional, ya sentada, bastan de momento para centrar adecuadamente el tema. 
Antes de pasar a examinar la repercusión de la doctrina citada en la actual regulación del control de legalidad y suspensión de acuerdos, volvemos a la sentencia de 2 de febrero de 1981 para destacar alguna de sus declaraciones en orden o relación a la incidencia de controles en el campo concreto de la autonomía financiera de las Corporaciones locales, y concretamente las siguientes:

A) «En consecuencia, dadas las diversas fuentes que nutren las Haciendas locales, así como su complementariedad, es aquí plenamente explicable la existencia de controles de legalidad, tanto en relación con la obtención y gestión de ingresos de carácter propio como con la utilización de los procedentes de otras fuentes".

B) «Por otro lado, y en conexión con los límites de la autonomía en materia económico-financiera, se plantea un tema clásico que es el relativo a la defensa del patrimonio del Estado o de los Entes públicos frente a sus administradores, defensa que lleva a limitar los poderes de disposición de las Administraciones públicas, sujetándolas a un control incluso de oportunidad».

De acuerdo con estos dos puntos, acaba declarando: que no es posible declarar en abstracto la inconstitucionalidad de controles que valoran incluso criterios de oportunidad, siempre que sean proporcionales como medida para la defensa del patrimonio. Hay aquí implícito un claro límite a la libre facultad de disposición patrimonial por los Entes locales.

\section{INCIDENCIA DE LAS SENTENCIAS EN LA REGULACIÓN VIGENTE}

Al tratar la incidencia de las sentencias en la legislación y reglamentos vigentes, antes enunciados y analizados, se establecerán una serie de conclusiones que fijen el tema, de modo que nos permitan pasar al punto siguiente de este estudio.

El primer efecto de la sentencia de 2 de febrero de 1981, en el orden que hemos señalado, es el de permitir interpretar el alcance del artículo 8..$^{\circ}$ del Real Decreto-ley de 16 de enero de 1981 (BOE del 31), y, por tanto, de la reciente Ley de 28 de octubre, ya que las puntualizaciones en torno a la concurrencia de intereses centra el alcance del apartado a), en cuanto que exige, junto con la infracción de leyes, la concurrencia de la circunstancia de que los actos o 
acuerdos de las Corporaciones locales afecten directamente a materias de la competencia del Estado. Lo que inicialmente parecía una restricción muy patente de las facultades de intervención estatal frente a los acuerdos de los Entes locales, queda adecuadamente determinado por la jurisprudencia.

Hay que tener en cuenta que el Real Decreto-ley de 16 de enero de 1981 solamente regulaba los casos de suspensión, pero no recoge, como hacen el Real Decreto 2238/80, de 10 de octubre, sobre los Delegados del Gobierno, y el Estatuto de Gobernadores civiles del 22. de diciembre siguiente, las facultades de impugnación o ejercicio de acciones legales y recursos procedentes ante los Tribunales en defensa de la Constitución y el Ordenamiento jurídico, contra los acuerdos de los Entes territoriales. Defecto que ha subsanado la Ley 40/1981, de 18 de octubre, que, sin embargo, va más lejos que las sentencias del Tribunal Constitucional, al convertir la suspensión en mera impugnación por parte del Gobierno.

De otro lado, la sentencia de 29 de abril de 1981 acaba de deslindar el tema de la suspensión de acuerdos del tema del control de legalidad, antes totalmente confundidos. La suspensión queda como una forma de control de legalidad, fuerte, y que sigue ligada por el artículo 118 de la Ley de la Jurisdicción Contenciosa a una impugnación procesal, pero no como una necesidad o como vía única de esta impugnación, pero que ya vemos que según la Ley 40 la suspensión es consecuencia de la ley.

Las sentencias del Tribunal Constitucional relacionan lo que la legislación y reglamentación estatal no habían sabido tratar de modo unitario: la suspensión de acuerdos como forma extraordinaria de control que exige algo más que la simple infracción de ley y el control de legalidad como una cuestión más genérica. A fuer de ser reiterativos hay que repetir que la nueva Ley, sustitutiva del Real Decreto, solamente concede al Estado la segunda fórmula: el simple control de legalidad, con dos formas de impugnación, una fuerte, que apareja la suspensión, y otra simple, de mera impugnación.

De esta doctrina cabe también señalar como inconstitucional la suspensión de acuerdos de las Corporaciones locales por las Comunidades autónomas, en los casos de los apartados 1 y 2 de los artículos 362 de la Ley de Régimen local, directamente y sin utilización de la vía del artículo 118 de la LJCA, cosa lógica, por otra 
parte, ya que estos supuestos suponían el establecimiento de una vía administrativa de alzada impropia, que hoy no puede subsistir.

Finalmente, la sentencia de 2 de febrero influye en la interpretación dada por la Dirección General de Administración Local del Ministerio de Administración Territorial, que mediante Resolución de 6 de marzo de 1981 suspende un acuerdo del Ayuntamiento de Madrid, por entender que en diversos aspectos - retribuciones, estatuto y huelgas de funcionarios- invade con su regulación materias reservadas constitucionalmente a la ley $\mathrm{y}$, por tanto, de exclusiva competencia del Estado.

\section{EL ACTUAL PROYECTO DE LEY DE BASES DE LA ADMINISTRACION LOCAL}

No cabe duda de que la publicación del Real Decreto-ley y Reales Decretos mencionados, así como el tiempo transcurrido y las sentencias del Tribunal Constitucional, han proporcionado datos y experiencias al Gobierno para afrontar el proyecto de la tan reclamada Ley de Bases del Régimen de las Administraciones locales.

Interesa aquí, en la línea asumida, ver el tratamiento que el proyecto of rece respecto del control de legalidad y, consiguientemente, de la suspensión de acuerdos.

\section{El CONTROL DE LEGALIDAD PROPIAMENTE DICHO}

Al respecto, el proyecto de ley dedica su capítulo II del título III a la suspensión de acuerdos y ejercicio de acciones, siendo los artículos clave en la cuestión el 47 y 48, en lo que se refiere a la competencia estatal en la materia.

En el artículo 47 se contempla la posibilidad de que por las Entidades locales se infrinja la legislación del Estado, en cuyo caso, si así lo considera la Administración del Estado, puede requerir a la Entidad interesada para que revoque, anule o suspenda el acuerdo, motivando el requerimiento y especificando la disposición en que se fundamenta, todo ello dentro del plazo marcado desde la recepción del correspondiente acuerdo. Si la Entidad no atiende el requerimiento, la Administración del Estado puede impugnar el acto o acuerdo directamente ante la Jurisdicción Contencioso-administrativa. 
Las mismas atribuciones se confieren a las Comunidades autónomas en orden a su propia legislación. Este hecho parece concretar que las transferencias de las competencias de suspensión del artículo 362, 1, 2 y 4, de la LRL, sólo corresponde en el ámbito de los intereses comunitarios.

El artículo 48 contempla el caso de que los actos y acuerdos de las Entidades locales constituyan infracción de las leyes y afecten directamente a materias de la competencia del Estado o de las Comunidades autónomas, estableciendo que pueden, entonces, ser impugnados directamente ante la Jurisdicción Contenciosa, bien por la Administración del Estado, bien por la Comunidad autónoma, de acuerdo con sus respectivas competencias. La impugnación supone la suspensión del acto o acuerdo, que debe ser ratificada o levantada por el Tribunal antes de treinta días.

Aparentemente, los dos artículos parecen incidir en el mismo campo, pues, en términos generales, una infracción de ley del Estado, como señalamos en ocasión anterior, puede estimarse una invasión del campo de competencia legislativa del Estado. Sin embargo, ante una reflexión más detenida se pueden dar ejemplos de infracciones de leyes del Estado que no vayan acompañadas de incompetencia o de invasión de competencias estatales. De este supuesto, pues, debe partir el proyecto de ley. Por ello, en el caso de infracción de ley, el artículo 27, citado, no recoge la suspensión del acto o el acuerdo, sino que simplemente establece la impugnación de los mismos, tras requerimiento previo a la Entidad local, ante la Jurisdicción Contenciosa, ante la cual, naturalmente, cabe solicitar la suspensión del acuerdo o acto recurrido.

Creo que este artículo deja a salvo dos cuestiones importantes:

a) La función o competencia del Estado de velar por el cumplimiento de las leyes, reduciéndola al campo de las estatales, y la misma función de las Comunidades autónomas en el ámbito de las suyas; y

b) La función de juzgar el principio de legalidad, final y originariamente, corresponde al Poder judicial o a los Tribunales. Este sistema permite a los Tribunales ejercer la función que les atribuye el artículo 106 de la Constitución, a través de una acción otorgada al Estado y Entes territoriales, conforme al principio que exige de una impugnación previa de los actos administrativos y acorde con un criterio amplio de control, que no es el totalmente abierto de una acción popular o de fiscalización directa. 
En cambio, el artículo 48, acorde con el $8 .^{\circ}$ del Real Decreto-ley $3 / 1981$, de 16 de enero, recoge el criterio jurisprudencial de la sentencia de 29 de abril de 1981, al establecer la suspensión del acto o acuerdo cuando concurre la doble circunstancia de infracción de ley e incompetencia de la Entidad local. Suspensión que, además, puede ratificar o levantar el Tribunal. No es la suspensión, ya, una competencia del Estado o de la Comunidad autónoma, sino una consecuencia de la impugnación y de la doble concurrencia señalada. No hay, por tanto, ningún ataque a la autonomía municipal o provincial, sino una concurrencia lógica del principio de legalidad y, además, revisable de inmediato por los Tribunales antes de entrar en el fondo de la cuestión. La gravedad de la infracción, se puede decir, lleva aparejada una presunción de ilegalidad que determina la suspensión automática, revisable por el Tribunal. La Ley 40/1981 es la que remarca el hecho de que la suspensión no es un acto del Gobierno, sino consecuencia de la impugnación y de la previsión legal, y es conforme al proyecto de ley de Régimen local con esta Ley, aun cuando realmente el proyecto de ley de Régimen local es anterior en el tiempo, lo que hace pensar que la aprobación de la Ley 40/1981 en este aspecto es un sistema de la posible aceptación del artículo 48 del proyecto.

El proyecto de ley parece, pues, consecuente con la doctrina mantenida por el Tribunal Constitucional, así como por la Ley 40/ 1981, y dejan el juicio final a cada cuestión planteada en el Poder judicial, a quien corresponde juzgar conforme al artículo 117 de la Constitución vigente.

Sin embargo, el proyecto de ley, acorde con la legislación vigente en materia económico-administrativa, mantiene, en su artículo 85, el conocimiento por los Tribunales Económico-administrativos de los recursos contra acuerdos definitivos de las Entidades locales en materia de imposición y ordenación de sus tributos. Aquí sí que hay un control directo de legalidad de estos actos por la Administración del Estado y, por tanto, con posibilidad de suspensión e incluso de anulación o revocación a través de esta vía de recurso, sin perjuicio de los recursos jurisdiccionales. La justificación de este control debe encontrarse en que el poder tributario de las Entidades locales es un poder derivado, que, conforme al artículo 133 de la Constitución, corresponde originariamente al Estado. 


\section{OTRAS CUESTIONES RELACIONADAS CON EL CONTROL DE LEGALIDAD}

El proyecto de ley no solamente nos marca la pauta general que acabamos de examinar en orden al control de legalidad y suspensión de acuerdos, sino que a través de su articulado fija y concreta una serie de competencias del Estado en orden al ámbito de la Administración local, que permiten a su vez concretar competencias que de ser quebrantadas darían motivo a la suspensión de acuerdos municipales o provinciales, a través de la correspondiente impugnación.

No es fácil sintetizar el contenido de los artículos del proyecto que implican la existencia de zonas en que la actividad de la Administración del Estado y las Entidades locales pueden confluir y dar origen a la intervención de la primera sobre la segunda; sin embargo, cabe establecer tres líneas generales mantenidas en este campo por el proyecto de ley:

a) Declaración de aplicación de la legislación estatal a las Entidades locales en determinadas materias.

b) Posibilidad de competencias o actividades compartidas por las Entidades locales con otras Administraciones públicas.

c) Establecimiento de unas competencias concretas del Estado o de determinados controles sobre las Entidades locales.

\section{A) Legislación estatal aplicable}

El proyecto de ley especifica una serie de materias que corresponden, conforme al artículo 149 de la Constitución, a la competencia del Estado, como de aplicación a través de las leyes estatales a las Entidades locales, en orden al régimen administrativo y a la Hacienda de las mismas.

El proyecto no hace más que remachar, en lo que se refiere a estos dos órdenes o campos de la organización administrativa y económica, la superioridad de las leyes estatales y su aplicación general o básica en todo el territorio nacional.

Las declaraciones concretas de aplicación de la legislación estatal en los órdenes señalados se contienen en los artículos 40 y 78 del proyecto.

El primero, referido al régimen administrativo de las Entidades locales, señala que éstas se regirán por la legislación que dicte el Estado, al amparo y en los términos previstos en el artículo 149, 
1, 18, de la Constitución y por la legislación que dicten las Comunidades autónomas, de acuerdo con lo establecido en las leyes del Estado y en sus respectivos Estatutos, sobre las siguientes materias:

a) Régimen estatutario de los funcionarios.

b) Procedimiento administrativo.

c) Expropiación forzosa.

d) Contratos y concesiones administrativas.

e) Responsabilidad administrativa.

He aquí, pues, la concreción de unas materias en donde las facultades de control y suspensión en favor de la Administración del Estado y de las Comunidades autónomas sobre los actos de las Entidades locales son claras. De otra parte, el artículo destaca el contenido unitario que a estos temas debe otorgar la legislación estatal, constituyendo así las bases que ésta establezca en estas materias y los intereses generales predominantes sobre los particulares de otras Entidades territoriales o de sus sectores sociales.

El segundo artículo, el 78 del Proyecto, establece que las Haciendas locales se regirán: a) por la presente ley; b) por la Ley General Tributaria; c) por la ley del Estado que regule el sistema tributario local; d) por los Reglamentos generales dictados en desarrollo de la Ley General Tributaria y por el propio de cada tributo, y $e$ ) por la ordenanza fiscal reguladora de cada tributo y que dicte la correspondiente Entidad local de acuerdo con lo previsto en la ley. Por último, en su párrafo segundo, indica el carácter supletorio de la Ley General Presupuestaria.

El peso de la regulación tributaria, financiera y presupuestaria del Estado sobre las Entidades locales es claro y terminante. Es más, el proyecto, en su artículo 80 , establece una serie de límites y principios que debe tener en cuenta el sistema tributario local, que constituyen en el fondo materia de control estatal sobre la actividad tributaria de los Entes locales.

Como punto final, el artículo 81, aun cuando referido a materia tributaria, abunda en la aplicación de los principios de legalidad y de reserva de ley; y el artículo 82 establece la facultad de dictar disposiciones interpretativas de las Leyes, Reglamentos y Ordenanzas en materia tributaria del Ministerio de Hacienda en el ámbito de su competencia.

En definitiva, en materia tributaria el control de legalidad es más intenso y extenso, y en las interpretaciones que el Estado pue- 
da adoptar sobre los acuerdos locales no sólo se tendría en cuenta la legislación, sino también los reglamentos, ordenanzas aclaratorias dictadas por el Estado o sus órganos.

\section{B) Competencias compartidas}

Como venimos abundando a través de este trabajo, el tema de las competencias se ha convertido en pieza clave de la nueva estructura estatal, y no sólo por el distinto tipo de los intereses que competen al Estado y sus Entes territoriales. Así, resulta que entre el Estado y los citados Entes se dan ámbitos competenciales concurrentes o competencias compartidas en las que el roce o conflicto puede ser más fácil (6).

Estas competencias compartidas vienen reconocidas en el proyecto de ley en el artículo 21, respecto de los Municipios, bien por la naturaleza de la actividad, bien como resultado de la ley y, en particular, en los campos de la educación, cultura, vivienda, sanidad y medio ambiente:

El artículo 35 también reconoce la actividad de la Diputación en el marco de la legislación estatal y las competencias compartidas con las Comunidades autónomas.

Pero tanto uno como otro precepto recogen además la posibilidad de que las Entidades locales asuman competencias delegadas o transferidas de la Administración del Estado, en el ámbito de sus intereses. El artículo 21, en este aspecto, prevé que la disposición o acuerdo en que se determine la delegación o transferencia de funciones o servicios especifique las condiciones en que la misma se realiza y la legislación aplicable.

De acuerdo, por tanto, con estos preceptos, y tenido en cuenta el artículo 150 de la Constitución, que en su punto 2 establece, en orden a las transferencias o delegaciones de facultades o competencias estatales a las Comunidades autónomas, que la ley preverá las formas de control que se reserve el Estado, resultaría que éste puede controlar el ejercicio de las actividades, funciones o competencias transferidas o delegadas en las Entidades locales.

(6) SÁnchez díaz, José-Luis: "Competencia y Autonomía», Revista de Estudios DE LA Vida LoCAL, núm. 205 (1980), págs. 87 y sigs. 


\section{C) Competencias estatales}

El proyecto establece una serie de competencias estatales que se mueven principalmente en el campo de la autorización o control en materias de Régimen local, principalmente de control en materia tributaria y financiera, conforme a la tendencia que con anterioridad ha quedado expuesta.

En el orden de competencias estatales concretas destacan aquellas que le corresponden en autorización de la creación de Municipios o decisión de la agrupación de los mismos en cuanto a la realización de obras o servicios transferidos o delegados; igualmente, las que se otorgan al Estado en cuanto a la resolución de conflictos de competencias entre Entidades locales de distintas Comunidades autónomas. En estas atribuciones la justificación reside, unas veces, en que el hecho afecta a la conformación del territorio nacional, o que excede del ámbito territorial de una Comunidad autónoma o, simplemente, que los servicios u obras corresponden a una transferencia o delegación estatal. La atribución de la resolución de conflictos de competencias apareja en el fondo un control de legalidad, al suponer la decisión una declaración de competencia o incompetencia en la actuación de una Entidad local.

Otras de las competencias que el proyecto de ley atribuye al Estado, tales como: la aprobación definitiva del régimen de Carta municipal o la intervención en la selección de los funcionarios de la Administración local, tanto de Cuerpos nacionales como de Cuerpos de las Entidades locales, mediante la convocatoria, establecimiento del contenido mínimo de los Tribunales de selección o concurso y su participación en los mismos, tienen no sólo un sentido controlador, sino que tienden a dar sentido unitario a las actuaciones de las Entidades locales en estos ámbitos.

El proyecto de ley establece en su título IV, «De las Haciendas locales", controles en materia tributaria y financiera, encaminados no solamente a velar por el ajuste a la ley, en estos campos, de la actividad de las Entidades locales, sino a obtener de las mismas una adecuada utilización de sus recursos tributarios y un buen rendimiento de los mismos, así como para garantizar la permanencia y conservación en los impuestos estatales o la previa autorización de las Corporaciones de crédito, en determinados casos. También a estos fines, y a los de permitir otros controles, obedecen las competencias que al Estado se le atribuyen en la determinación de la estructura de los presupuestos de las Entidades lo- 
cales y la obligación de que éstas remitan aquéllos a la Administración estatal.

Finalmente, los artículos 76 y 77, dentro del título III, capítulo VII, dedicado al régimen de intervención de las Entidades locales, permiten al Gobierno la adopción de medidas extraordinarias en cuanto las Entidades locales no cumplan con sus obligaciones constitucionales, o con las que las leyes estatales les impongan, o atenten gravemente al interés de España; también se permite la adopción de medidas para la regularización de la situación financiera de las Entidades locales en casos tasados que hacen suponer una mala situación económico-financiera.

En todos estos casos el Gobierno debe dar cuenta de la situación y medidas adoptadas al Senado.

Del contenido de estas últimas competencias o atribuciones se infiere claramente que la intervención estatal se produce en beneficio del interés general y también del provincial o municipal, cuando las Entidades locales por sí no satisfacen sus propios intereses.

\section{CONCLUSIONES SOBRE EL ESTADO DE LA CUESTION EN GENERAL}

En definitiva, de todo lo antedicho se deduce que en la actualidad el control de legalidad tiene, en primer lugar y con carácter general, dos acepciones, una jurídica y otra administrativa. Jurídicamente, determinar lo que es legal o ilegal corresponde a los Tribunales, es decir, al Poder judicial. Administrativamente, el control de legalidad requiere la atribución de funciones o competencias encaminada a velar por el cumplimiento de las leyes y al ejercicio de acciones para la declaración de ilegalidad de los actos de los Entes territoriales distintos del Estado; competencias y acciones que se atribuyen de acuerdo a la mayor o menor generalidad de los intereses que cada Administración pública debe cumplir. Acorde con esta doble acepción es la doctrina mantenida por el Tribunal Constitucional, y en su línea está el proyecto de ley de la Administración local.

Sin embargo, de todo lo expuesto se produce, en términos generales, una situación confusa que nos obliga a resumir y sintetizar, finalmente, las facultades de control, en la segunda acepción ya señalada. Por lo tanto, el Estado puede ejercer los siguientes controles en el momento actual y en la forma que se indica: 


\section{RESPECto DE LAS Comunidades autónomas}

a) Mediante el recurso de inconstitucionalidad contra las leyes, actos y disposiciones normativas con fuerza de ley (art. 161, 1, a, de la Constitución y Ley Orgánica del Tribunal Constitucional).

b) En el caso de delegación legislativa en las Comunidades autónomas, mediante el control que la ley estatal de delegación establezca.

c) Mediante el planteamiento de conflictos de competencia, positivos o negativos, ante el Tribunal Constitucional (art. 161, 1, c, de la Constitución y LOTC).

d) Mediante la impugnación de las disposiciones sin fuerza de ley y resoluciones de las Comunidades autónomas ante el Tribunal Constitucional, conforme al artículo 161, 2, de la Constitución y los artículos 76 y 77 de la LOTC, con la duda de si dicha impugnación se reduce o no a los casos de inconstitucionalidad. La impugnación apareja la suspensión de la disposición.

e) Mediante el ejercicio de las acciones legales que corresponden al Estado respecto de los acuerdos y disposiciones normativas de rango inferior a ley y actos de las Comunidades autónomas y Entidades de ellas dependientes, que se estimen ilegales o contrarios a los intereses estatales.

f) Mediante el control que el Estado se reserve respecto de las funciones transferidas o delegadas (art. 150, 2, de la Constitución).

g) Mediante la adopción de medidas que se estimen necesarias en caso de incumplimiento de sus obligaciones por parte de las Comunidades autónomas, condicionadas a la aprobación senatorial (artículo 155 de la Constitución).

h) Mediante el conocimiento de los recursos económico-administrativos de impugnación por particulares de los acuerdos definitivos de las Comunidades autónomas en materia de imposición y ordenación de tributos y presupuestaria. Sistema en el que cabe la suspensión directa del acto o acuerdo correspondiente.

i) Mediante las competencias establecidas o que se establezcan por ley en orden a autorizaciones, aprobaciones y decisiones sobre actos o resoluciones de las Comunidades. 


\section{Respecto de los Entes locales}

Naturalmente, en orden a los Entes locales se dan facultades de control que hemos visto en orden a las Comunidades autónomas, pero en aras de una mayor claridad enunciaremos todos los controles que caben.

a) Suspensión de los actos de los Entes locales cuando concurra la doble circunstancia de infracción de ley e invasión de competencias del Estado. La suspensión supone el inicio de un proceso contencioso-administrativo sobre la legalidad o no del acto y la procedencia o no de su suspensión. En definitiva, la suspensión es consecuencia de la previsión legal y de la impugnación.

b) Mediante el ejercicio de las acciones legales que corresponden al Estado respecto de los acuerdos, actos y disposiciones normativas de las Corporaciones locales.

c) Mediante el control que el Estado se reserve en cuanto a facultades o funciones transferidas o delegadas.

d) Mediante el recurso económico-administrativo en la forma y casos vistos respecto de las Comunidades autónomas.

e) Mediante las competencias que en orden a la aprobación, autorización o decisión sobre actos de los Entes locales se atribuyan al Estado por ley.

También respecto a los Entes locales prevé el proyecto de ley de Régimen local la atribución al Gobierno de la adopción de medidas necesarias en caso de incumplimiento de sus obligaciones por los Entes locales, en una extensión del artículo 155 de la Constitución y como reflejo de la máxima: «Quien puede lo más, puede lo menos». No obstante, la norma no está aprobada.

En definitiva, las competencias abstractas que la Constitución señala como propias del Estado deben concretarse por las leyes, de modo que en orden al control de legalidad simple se señale el modo de ejercicio de las acciones legales del Estado contra los actos y acuerdos de los Entes territoriales; es decir, los casos en que dicho ejercicio procede y el procedimiento a seguir.

Igualmente es necesaria esta concreción de competencias, pues facilitará el deslinde con las de los Entes territoriales y la posibilidad de determinar la procedencia o no de la suspensión de acuerdos y, al mismo tiempo, las funciones de cada Ente y del Estado en las materias compartidas o competencias concurrentes.

Es necesaria la fijación de los sistemas de control de las funcio- 
nes o facultades delegadas por el Estado y si entre ellas persiste la vía del recurso jerárquico o de alzada impropio.

De aquí que con insistencia hayamos dicho que el tema es en el fondo una cuestión de competencias, ya que su concreción permite el ejercicio del control de legalidad por el Estado o por las Comunidades autónomas, en su caso, e incluso por los Tribunales. La fijación de las competencias de un Ente o de un órgano no sólo supone su capacidad de acción, sino que delimita su campo de acción $\mathrm{y}$ el de los restantes Entes u órganos, en sentido positivo o negativo.

Las disposiciones legales y reglamentarias examinadas y el proyecto de ley de Administración local son ejemplos que permiten perfilar el problema y plantear no sólo sus líneas generales, sino centrarse en puntos más específicos. 